\title{
Isolation of Chlamydia trachomatis from the male urethra
}

\author{
M. D. AlANi, S. DAROUGAR, D. C. MACD. BURNS, R. N. THIN, AND \\ HELEN DUNN \\ From St Bartholomew's Hospital and Institute of Ophthalmology, London
}

SUMMARY Chlamydia trachomatis was isolated from $26 \%$ of urethral swabs taken from 509 men with urethritis. The highest yield of $68 \%$ was obtained from a selected group of men with nonspecific urethritis (NSU) who had a frank urethral discharge. This is higher than in previous reports, and is significantly higher than the isolation of $\boldsymbol{C}$. trachomatis from men with less severe urethritis. The higher yield was similar to $C$. trachomatis isolation rates reported among patients with severe trachoma in hyperendemic areas. Men with a previous history of NSU had low isolation rates. Overall, $30 \%$ of 385 men with NSU had positive chlamydial culture results, $7 \%$ of 59 men with gonococcal urethritis alone were Chlamydia-positive, $15 \%$ of 59 men with gonorrhoea followed by NSU (post-gonococcal urethritis) were Chlamydia-positive, and only $3 \%$ of 61 men without urethritis harboured Chlamydia. Swabs taken from the cervical os of 28 of 108 female contacts of men with NSU had a positive result for $C$. trachomatis. Significantly more pairs of sexual partners had the same chlamydial culture result than had different results. The chlamydial isolation rate was higher among men admitting a casual sexual contact than in men claiming only regular partnerships. The findings provide further evidence for the sexual transmission of $C$. trachomatis and for its aetiological role in NSU.

\section{Introduction}

Non-specific urethritis (NSU) is the commonest sexually transmitted disease in England (Department of Health and Social Security, 1976) but the cause in half of the cases is not clear. Since 1965 (Dunlop et al., 1965), Chlamydia trachomatis has been isolated from the urethral discharge in men with this condition but its exact pathological role is in doubt. To help to elucidate this problem we investigated 591 men with and without urethritis, and 121 of their female partners, for the presence of genital Chlamydia.

\section{Material and methods}

\section{PATIENTS}

Included in the investigation were 591 unselected heterosexual men who attended the Department of Genital Medicine at St Bartholomew's Hospital of

Address for reprints: Dr R. N. Thin, St Bartholomew's Hospital, London EC1

Received for publication 16 December 1976 their own accord between 18 April 1973 and 19 November 1975. This comprised 530 men with urethritis and a control group of 61 men without urethritis on examination and investigation. Men who had had urethritis and/or antibiotics during the previous six months were excluded. The patients were divided into groups according to the clinical and laboratory findings (excluding chlamydial results), date of admission, age, marital state, nationality, and severity and duration of the urethral discharge. The influence of casual and regular partners was also studied. Partners with whom patients had had sexual intercourse only once or twice within the previous three months were regarded as casual. Partners with whom patients had had more frequent intercourse during this period were regarded as regular. Chlamydial cultures taken from the cervical os of 121 female contacts of men with NSU were also investigated.

\section{CLINICAL ASSESSMENT AND}

LABORATORY INVESTIGATIONS

On the man's first attendance the history was taken including details of genitourinary symptoms and 
sexual contacts. After genital and general examinations and before the patient passed urine, specimens were collected and examined as follows:

1. Urethral secretion was spread on a slide, stained by Gram's method and examined microscopically for the presence of leucocytes, bacteria, and yeasts.

2. A wet film was examined microscopically for Trichomonas vaginalis.

3. Charcoal swabs of meatal secretion were placed in Stuart's transport medium. Within 24 hours these were plated on to the selective medium described by Riddell and Buck (1970). Neisseria gonorrhoeae were identified by colonial appearance, oxidase reaction, Gram stain appearance, and by sugar fermentation reactions using serum-free medium (Flynn and Waitkins, 1972).

4. Intraurethral secretion was collected using the swab described by Dunlop et al. (1972a) which was inserted about $5 \mathrm{~cm}$ into the urethra and then placed in a plastic capsule containing 2 SPS transport medium (2 SP+ $3 \%$ fetal bovine serum and antibiotics) (Darougar et al., 1972). The capsules were then stored in a liquid nitrogen refrigerator $\left(-180^{\circ} \mathrm{C}\right)$ until being transferred to the laboratory where they were placed in a refrigerator at $-70^{\circ} \mathrm{C}$ for between three and six weeks until inoculation. Monolayers of irradiated McCoy cells were prepared in flat-bottomed tubes using the method of Gordon et al. (1969). Each clinical specimen was inoculated into two tubes, using the simplified one-passage technique of culture in irradiated McCoy cells (Darougar et al., 1971). The inoculated cells were incubated at $35^{\circ} \mathrm{C}$ for approximately 60 hours and then fixed and stained with Giemsa. The Giemsastained monolayers were examined for the presence of chlamydial inclusions, using a microscope with a $10 \times$ objective, $2 \times$ optovar, $8 \times$ oculars, and dark-field illumination. Clinical investigations were only carried out after the patients had held their urine for at least four hours; otherwise they were examined and investigated in the early morning.

The techniques used for investigating the women were reported previously (Burns et al., 1975).

Chlamydial isolation was not routinely attempted during follow-up after treatment.

\section{Diagnosis and classification of NSU}

The diagnosis of NSU was established by the presence of:

1. A urethral discharge. When this formed a bead of pus or mucopus at the meatus it was classed as severe.

2. Ten or more leucocytes per high power field in Gram-stained smears and the absence of gonococci and yeasts.

3. Absence of trichomonads on a wet film.

4. Failure to culture $N$. gonorrhoeae.

5. In cases of urethritis following gonorrhoea, the diagnosis of NSU was only made 14 days or more after the treatment for gonorrhoea.

\section{Results}

\section{OVERALL RESULTS IN MEN}

Twenty-one men were excluded because the chlamydial cultures were overgrown by other organisms or the culture cells had failed to grow satisfactorily. This left $\mathbf{5 7 0}$ patients to be investigated. For the same reason, 13 of the 121 women were excluded.

The 570 men investigated included (Table 1) 385 with NSU; $116(30 \cdot 1 \%)$ harboured $C$. trachomatis. Fifty-nine patients had gonococcal urethritis alone; only four $(6.8 \%)$ had a positive chlamydial culture result. Fifty-nine had gonorrhoea followed by NSU (as previously defined) and nine $(15 \cdot 2 \%)$ harboured Chlamydia. Only two of six patients with Reiter's syndrome had a positive chlamydial culture result. In the control group only two $(3.3 \%)$ of 61 men had a positive chlamydial culture result. These results (Table 1) indicate a significant association between urethral Chlamydia and NSU, and between absence of Chlamydia and no urethritis (excluding Reiter's syndrome $\left.\chi_{3}{ }^{2}=35.6 ; \mathrm{P}<0.001\right)$.

There was no difference in chlamydial isolation rates between British and foreign men, and none between single and married men. Their age distribution and countries of origin conformed with those of

Table 1 Incidence of $\mathrm{C}$. trachomatis in various sexually transmitted diseases

\begin{tabular}{lrrr}
\hline & & \multicolumn{2}{c}{ Chlamydia positive } \\
\cline { 3 - 4 } Disease & Total & No. & $\%$ \\
\hline NSU & 385 & 116 & $30 \cdot 1$ \\
Gonorrhoea & 59 & 4 & $6 \cdot 8$ \\
Gonorrhoea followed by NSU & 59 & 9 & $15 \cdot 2$ \\
Reiter's syndrome & 6 & 2 & $33 \cdot 3$ \\
No urethritis & 61 & 2 & $3 \cdot 3$ \\
& 570 & 133 & \\
\hline
\end{tabular}

Excluding Reiter's syndrome $\chi_{3}{ }^{2}=35.6$; P 0.001 
all men attending the department. Therefore, no relationship was established between the age or country of origin and the isolation of $C$. trachomatis.

MEN WITH CHLAMYDIAL-POSITIVE NSU

AND MATCHED CASES WITH

CHLAMYDIAL-NEGATIVE NSU

The cases of the men with chlamydial-positive NSU were matched with the same number of cases with chlamydial-negative NSU (matched for age, country of birth, marital state, and time of presentation) and examined in greater detail. Full details were not available for all cases but chlamydial isolation could be related to severity of urethral discharge in 184 patients (Table 2). A significantly higher

Table 2 Chlamydial isolation related to severity of discharge in 184 men with NSU

\begin{tabular}{lcclll}
\hline & \multicolumn{3}{l}{ Amount of discharge } \\
\cline { 2 - 3 } Chlamydia & \multicolumn{3}{l}{ Slight } & & \multicolumn{2}{l}{ Severe } \\
\cline { 2 - 3 } \cline { 5 - 6 } & No. & $\%$ & & No. & $\%$ \\
\hline Positive & 69 & 46.0 & & 23 & 67.7 \\
Negative & 81 & 54.0 & 11 & $32 \cdot 3$ \\
Total & 150 & & 34 & \\
\hline
\end{tabular}

With Yates's continuity correction $\chi_{1}^{2}=5 \cdot 29, P<0.05$

positive isolation rate of $67.7 \%$ was obtained from those with a severe discharge compared with those with a slight discharge $(46.0 \%)$. The duration of discharge could be examined in 200 patients; C. trachomatis was isolated significantly more often from men who had had a discharge for eight or more days than from men who had had a discharge for a shorter time (Table 3). Chlamydial isolation was then related to previous history of urethritis. Table 4 shows the history of urethritis given by all 116 men with chlamydial-positive NSU compared with the history given by matched cases with chlamydialnegative NSU. A significantly higher chlamydial isolation rate $(55.6 \%)$ was obtained from men with no previous episodes compared with men who had had two or more previous episodes $(12 \%)$.

Table 3 Chlamydial isolation: duration of urethral discharge before isolation of Chlamydia in 200 men with $N S U$

\begin{tabular}{|c|c|c|c|c|c|c|}
\hline \multirow{3}{*}{ Chlamydia } & & \multicolumn{5}{|c|}{ Duration of discharge (days) } \\
\hline & None & $\leqslant 7$ & $8-14$ & \multicolumn{2}{|c|}{$15-28$} & $28+$ \\
\hline & No. $\%$ & No. $\%$ & No. \% & & $\%$ & No. \% \\
\hline $\begin{array}{l}\text { Positive } \\
\text { Negative } \\
\text { Total }\end{array}$ & $\begin{array}{ll}18 & 38 \\
29 & 62 \\
47 & \end{array}$ & $\begin{array}{rr}56 & 50 \\
56 & 50 \\
112 & \end{array}$ & $\begin{array}{rr}9 & 53 \\
8 & 47 \\
17 & \end{array}$ & $\begin{array}{l}7 \\
2 \\
9\end{array}$ & $\begin{array}{l}78 \\
22\end{array}$ & $\begin{array}{rl}10 & 67 \\
5 & 33 \\
15 & \end{array}$ \\
\hline
\end{tabular}

(Comparing isolation rates in those with no discharge, discharge for less than eight days and discharge for eight or more days, $\chi_{2}^{2}=6.55$; $P=0.04$ )
Table 4 Chlamydial isolation related to previous urethritis in 232 men with NSU

\begin{tabular}{|c|c|c|c|}
\hline \multirow[t]{2}{*}{ History } & \multicolumn{2}{|c|}{$\begin{array}{l}\text { Chlamydia- } \\
\text { positive }\end{array}$} & \multirow{2}{*}{$\frac{\begin{array}{l}\text { Chlamydia- } \\
\text { negative }\end{array}}{\text { No. }}$} \\
\hline & No. & $\%$ & \\
\hline (a) No previous urethritis & 79 & $55 \cdot 6$ & 63 \\
\hline (b) NSU alone once before & 18 & $51 \cdot 4$ & 17 \\
\hline (c) NSU twice or more before & 3 & $12 \cdot 0$ & 22 \\
\hline (d) Gonorrhoea alone before & 11 & $57 \cdot 8$ & 8 \\
\hline \multirow{2}{*}{ (e) NSU and gonorrhoea before } & 5 & $45 \cdot 4$ & 6 \\
\hline & 116 & & 116 \\
\hline
\end{tabular}

$\chi_{4^{2}}=16.84 ; P<0.005$

$\chi_{3}{ }^{2}=16.74 ; P<0.001$ (excluding (e))

MALE AND FEMALE CONTACTS

Among the 108 female contacts of men with NSU, $28(25.9 \%)$ had positive culture results for $C$. trachomatis.

Table 5 Chlamydial isolation from men with NSU and their partners

\begin{tabular}{lll}
\hline Chlamydia in women & \multicolumn{2}{l}{ Chlamydia in men } \\
\cline { 2 - 3 } & Positive & Negative \\
\hline Positive & 14 & 14 \\
Negative & 17 & 63 \\
\hline
\end{tabular}

With Yates's continuity correction $\chi_{1}^{2}=7.03 ; P<0.01$

Table 5 shows a significant correlation between the chlamydial culture results from men with NSU and from their female contacts. There was a higher rate of positive chlamydial culture results from patients who had had one or more casual contacts compared with patients who had only one regular partner (Table 6), but this was not significant.

Specimens for chlamydial isolation were also taken from 41 men with chlamydial-positive NSU one to eight weeks after finishing treatment with $300 \mathrm{mg}$ triple tetracycline (Deteclo) twice daily for 21 days. All gave negative results.

Table 6 Chlamydial isolation related to sexual partners within the preceding 3 months: review of 207 cases

\begin{tabular}{|c|c|c|c|c|}
\hline \multirow[t]{2}{*}{ Chlamydia } & \multicolumn{2}{|c|}{$\begin{array}{l}\text { Wife and/or } \\
\text { regular partner }\end{array}$} & \multicolumn{2}{|c|}{$\begin{array}{l}\text { Casual contact } \\
\text { with or without } \\
\text { regular partner }\end{array}$} \\
\hline & No. & $\%$ & No. & $\%$ \\
\hline $\begin{array}{l}\text { Positive } \\
\text { Negative } \\
\text { Total }\end{array}$ & $\begin{array}{l}43 \\
51 \\
94\end{array}$ & 46 & $\begin{array}{r}66 \\
47 \\
113\end{array}$ & 58 \\
\hline
\end{tabular}

$\left(\chi_{1}{ }^{2}=2 \cdot 81: \quad P=0.09\right)$ 


\section{Discussion}

The $C$. trachomatis isolation rate in patients with NSU has been reported as up to $50 \%$ (Dunlop et al., 1972b; Holmes et al., 1975; Oriel et al., 1976). Hence there is doubt about the aetiology of chlamydial-negative cases of NSU.

We found that the chlamydial isolation rate from men with NSU was $30 \cdot 1 \%$. However, the isolation rate among those with a severe discharge reached the high level of $67.7 \%$ which is greater than previously reported. The difference between those with severe and those with slight NSU contrasts with the findings of Richmond et al. (1972) and Oriel et al. (1972) who found no relationship between severity of discharge and chlamydial isolation rate, but it agrees with the observations of Schachter et al. (1975) who reported a higher isolation rate among men with frank discharge.

These findings resemble observations made on patients suffering from hyperendemic trachoma. Darougar et al. (1976), examining patients in southern Iran and in Tunisia, found that the overall isolation rate of $C$. trachomatis in patients with active trachoma was $40 \%$ and $32 \%$ respectively, but after selecting patients with severe trachoma the isolation rate increased to a high level of $68 \%$ and $72.7 \%$ respectively.

In this study we found that previous NSU may affect the isolation rate of $C$. trachomatis (Table 4). In patients who had had two or more previous episodes of NSU, the chlamydial isolation rate was a quarter of the rate in those who were infected for the first time $(12 \%$ compared with $55.6 \%)$. This difference may have been affected by our excluding men who had had urethritis during the previous six months, but it agrees with the results of work carried out on models in the study of chlamydial infections of the eye and genital tract in men. Monnickendam and Darougar (in preparation), studying the immunopathology of chlamydial infections in guinea-pigs infected with guinea-pig inclusion conjunctivitis (caused by a member of the Chlamydia psittaci group), found that during the primary infection in fresh animals, chlamydial inclusions could be shown in over one-quarter of epithelial cells for a period of three to four weeks, but in animals who were reinfected once or more, the number of infected cells decreased to 2 or $3 \%$ and the chlamydial inclusions could be detected for only a short period of three to five days.

Our results indicate that by selecting patients with severe NSU and excluding those who have had two or more previous attacks, the rate of isolation of C. trachomatis may be increased to a level of $70 \%$ or more.
Our isolation rate $(3.3 \%)$ of $C$. trachomatis from men without apparent urethritis was lower than the $5 \%$ quoted by Oriel et al. (1976) and 7\% of Holmes et al. (1975). Like both these groups not all our patients had early morning examinations, so our rate may have been affected by mild urethritis which could have been detected by this procedure.

The relationship between duration of symptoms and chlamydial isolation was highly significant and agrees with the observations of Richmond et al. (1972), Holmes et al. (1975), and Oriel et al. (1976). Oriel et al. (1976) suggested that the numbers of infective particles may increase with time, so increasing the recovery rate. Holmes et al. (1975) took repeated samples from a small group of patients before treatment but found no increase in the positive yield to support this suggestion. Dunlop et al. (1976) also took repeated samples and the second set of cultures yielded two cases with positive results among 13 investigated.

Significantly more pairs of sexual partners had the same chlamydial culture results than had differing results (Table 5). This is similar to the findings of Oriel et al. (1972).

Oriel et al. (1976) found C. trachomatis more often in men admitting recent partner change than in men denying such change. It is therefore interesting that the chlamydial isolation rate was higher in our series among men admitting to a casual contact than in men claiming only regular partnership(s) (Table 6), although the difference was not statistically significant.

We believe that the data in Table 1 provide strong evidence that $C$. trachomatis is sexually transmitted and is associated with NSU. Further evidence for its aetiological role in NSU is provided by the higher isolation rate in clinically severe cases, and further evidence for its sexual transmission is provided by its higher incidence in men with multiple partners and its correlation between pairs of sexual partners.

We are grateful to Professor Barrie R. Jones for his support and encouragement and to Monica Leighton, Computing Unit, St Batholomew's Hospital for carrying out the statistical calculations. The laboratory work was supported by a grant from the Department of Health and Social Security.

\footnotetext{
References

Burns, D. C. MacD., Darougar, S., Thin, R. N., Lothian, L., and Nicol, C. S. (1975). Isolation of Chlamydia from women attending a clinic for sexually transmitted disease. British Journal of Venereal Diseases, 51, 314-318.

Darougar, S., Jones, B. R., Kinnison, J. R., Vaughan-Jackson, J. D., and Dunlop, E. M. C. (1972). Chlamydial infection. Advances in the diagnostic isolation of Chlamydia, including TRIC agent, from the eye, genital tract, and rectum. British Journal of Venereal Diseases, 48, 416-420.
} 
Darougar, S., Kinnison, J. R., and Jones, B. R. (1971). Chlamydial isolates from the rectum in association with chlamydial infection of the eye or genital tract. I. Laboratory aspects, pp. 501-506. Excerpta Medica: Amsterdam.

Darougar, S., Woodland, R., Forsey, T., Dunn, H., Jones, B. R., and Allami, J. (1976). Isolation of $C$. trachomatis from ocular infections. In Proceedings of Conference on Non-gonococcal Urethritis and Related Oculo-genital Infections, 28-30 April, Lake Placid, New York, USA.

Department of Health and Social Security (1976). Report on the State of the Public Health for the Year 1975, pp. 47-51. HMSO: London.

Dunlop, E. M. C., Al-Hussaini, M. K., Garland, J. A., Treharne, J. D., Harper, I. A., and Jones, B. R. (1965). Infection of urethra by TRIC agent in men presenting because of non-specific urethritis. Lancet, 1, 1125-1128.

Dunlop, E. M. C., Goldmeier, D., Darougar, S., and Jones, B. R. (1976). Chlamydial infection of the genital tract in the mothers and fathers of babies suffering from ophthalmia neonatorum due to TRIC agent. In Sexually Transmitted Diseases, pp. 83-88. Edited by R. D. Catterall and C. S. Nicol. Academic Press: London.

Dunlop, E. M. C., Vaughan-Jackson, J. D., and Darougar, S. (1972a). Chlamydial infection. Improved methods of collection of material for culture from the urogenital tract and rectum. British Journal of Venereal Diseases, 48, 421-424.

Dunlop, E. M. C., Vaughan-Jackson, J. D., Darougar, S., and Jones, B. R. (1972b). Chlamydial infection. Incidence in nonspecific urethritis. British Journal of Venereal Diseases, 48, 425-428.

Flynn, J., and Waitkins, S. A. (1972). A serum-free medium for testing fermentation reactions in Neisseria gonorrhoeae. Journal of Clinical Pathology, 25, 525-527.
Gordon, F. B., Harper, I. A., Quan, A. L., Treharne, J. D., Dwyer, R. St. C., and Garland, J. A. (1969). Detection of Chlamydia (Bedsonia) in certain infections of man. I. Laboratory procedures: comparison of yolk sac and cell culture for detection and isolation. Journal of Infectious Diseases, 120, 451-462.

Holmes, K. K., Handsfield, H. H., Wang, S. P., Wentworth, B. B. Turck, M., Anderson, J. B., and Alexander, E. R. (1975). Aetiology of non-gonococcal urethritis. New England Journal of Medicine, 292, 1199-1205.

Oriel, J. D., Reeve, P., Powis, P., Miller, A., and Nicol, C. S. (1972) Chlamydial infection. Isolation of Chlamydia from patients with non-specific genital infection. British Journal of Venereal Diseases, 48, 429-436.

Oriel, J. D., Reeve, P., Wright, J. T., and Owen, J. (1976). Chlamydial infection of the male urethra. British Journal of Venereal Diseases, 52, 46-51.

Richmond, S. J., Hilton, A. L., and Clarke, S. K. R. (1972). Chlamydia infection. Role of Chlamydia Subgroup A in non-gonococcal and post-gonococcal urethritis. British Journal of Venereal Diseases, 48, 437-444.

Riddell, R. H., and Buck, A. C. (1970). Trimethoprim as an additional selective agent in media for the isolation of $N$. gonorrhoeae. Journal of Clinical Pathology, 23, 481-483.

Schachter, J., Hanna, L., Hill, E. C., Massad, S., Sheppard, C. W., Conte, J. E., Cohen, S. N., and Meyer, K. F. (1975). Are chlamydia infections the most prevalent venereal diseases? Journal of the American Medical Association, 231, 1252-1255. 